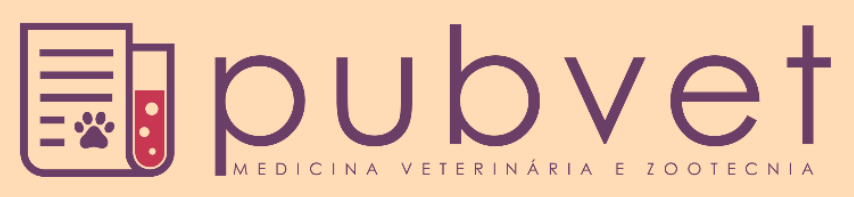

https://doi.org/10.31533/pubvet.v14n10a663.1-5

\title{
Sinais clínicos neurológicos, associados à leishmaniose visceral canina, em área endêmica: Relato de caso
}

\author{
Bianca Gomes da Silva $^{1 *} \bullet$, Jéssica Peçanha Nascimento ${ }^{2} \bullet$, Camila Maria dos $\operatorname{Santos}^{3}{ }^{\bullet}$, Judson \\ Matias de Arruda dos $\operatorname{Santos}^{4}{ }^{\circ}$, Eduardo de Castro Ferreira ${ }^{5,6}{ }^{\circ}$, Dina Regis Recaldes \\ Rodrigues Argeropulos Aquino ${ }^{70}$ \\ ${ }^{I}$ Aprimoranda em Clínica Médica e Cirúrgica, na Clínica Veterinária da Universidade Anhanguera Uniderp - Campo Grande, MS. \\ ${ }^{2}$ Aprimoranda em Patologia Clínica na Clínica Veterinária da Universidade Anhanguera Uniderp - Campo Grande, MS. \\ ${ }^{3}$ Mestranda em Doenças Infecciosas e Parasitárias pela Faculdade de Medicina, da Universidade Federal do Mato Grosso do Sul. \\ ${ }^{4}$ Graduando do Curso de Ciências Biológicas da Universidade Anhanguera Uniderp - Campo Grande, MS. \\ ${ }^{5}$ Docente do Programa de Pós-Graduação Stricto Sensu em Meio Ambiente e Desenvolvimento Regional da Universidade Anhanguera \\ Uniderp - Campo Grande, MS \\ ${ }^{6}$ Pesquisador da Fiocruz Mato Grosso do Sul, Fundação Oswaldo Cruz/ Ministério da Saúdel Brasil \\ ${ }^{7}$ Docente do Curso de Medicina Veterinária da Universidade Anhanguera Uniderp - Campo Grande, MS. \\ *Autor para correspondência, E-mail: biancagsvet@gmail.com
}

Resumo. A leishmaniose visceral canina (LVC) é uma doença causada por um protozoário do gênero Leishmania spp. Esta zoonose se apresenta com diversas manifestações clínicas no hospedeiro infectado, desde alterações cutâneas a alterações sistêmicas. Estudos com cães positivos para leishmaniose visceral demonstraram alterações no tecido nervoso desses animais. Este trabalho teve por objetivo relatar um caso de cão, naturalmente infectado por Leishmania spp., apresentando alterações neurológicas associadas a esse protozoário. O presente caso descreve-se por manifestação de sinais neurológicos de opstótono e tetania espástica em cão de área endêmica, naturalmente infectado por Leishmania spp. O diagnóstico parasitológico foi realizado após punção aspirativa por agulha fina (PAAF) de linfonodo poplíteo, por meio da visualização, em microscópio óptico, de formas amastigotas de Leishmania spp. Posteriormente confirmados pela reação em cadeia da polimerase (PCR) dirigida ao gênero Leishmania spp. A leishmaniose visceral canina é caracterizada por um espectro amplo e variável de sinais clínicos.

Palavras chave: canina, leishmaniose, PCR, tetania

\section{Neurological clinical signs associated with canine visceral leishmaniasis in an endemic area: Case report}

\begin{abstract}
Canine visceral leishmaniasis (CVL) is a disease caused by a protozoan of the genre Leishmania spp. This zoonosis presents with several clinical manifestations in the infected host, from skin changes to systemic changes. Studies with dogs positive for visceral leishmaniasis have shown changes in the nervous tissue of these animals. This study aimed to report a case of a dog, naturally infected by Leishmania spp., presenting neurological changes associated with this protozoan. The present case is described by the manifestation of neurological signs of opstotone and spastic tetany in a dog from an endemic area, naturally infected by Leishmania spp. The parasitological diagnosis was performed after aspiration puncture with a fine needle (FNAP) of a popliteal lymph node, through the visualization, in an optical microscope, of amastigote forms of Leishmania spp. Subsequently confirmed by the polymerase chain reaction (PCR) directed to the genus Leishmania. Canine visceral leishmaniasis is characterized by a wide and variable spectrum of clinical signs.
\end{abstract}

Keywords: canine, leishmaniasis, PCR, tetany 


\title{
Signos clínicos neurológicos, secundarios a leishmaniasis visceral canina, en un área endémica: Reporte de caso
}

\begin{abstract}
Resumen. La leishmaniasis visceral canina (CVL) es una enfermedad causada por un protozoo del género Leishmania spp. Esta zoonosis se presenta con varias manifestaciones clínicas en el huésped infectado, desde cambios en la piel hasta cambios sistémicos. Los estudios con perros positivos para la leishmaniasis visceral han demostrado cambios en el tejido nervioso de estos animales. Este estudio tuvo como objetivo informar un caso de un perro, naturalmente infectado por Leishmania spp., presentando cambios neurológicos asociados con este protozoo. El presente caso se describe por la manifestación de signos neurológicos de opstotona y tetania espástica en un perro de un área endémica, naturalmente infectado por Leishmania spp. El diagnóstico parasitológico se realizó después de la aspiración con aguja fina (FNAP) de los ganglios linfáticos poplíteos, a través de la visualización, en un microscopio óptico, de formas amastigotas de Leishmania spp. Posteriormente confirmado por la reacción en cadena de la polimerasa (PCR) dirigida al género Leishmania spp. La leishmaniasis visceral canina se caracteriza por un amplio y variable espectro de signos clínicos.
\end{abstract}

Palabras clave: canino, leishmaniasis, PCR, tetania

\section{Introdução}

A leishmaniose visceral canina (LVC) é uma zoonose que acomete o cão, causada por um protozoário do gênero Leishmania spp (Schimming \& Silva, 2012). É caracterizada como uma doença negligenciada com franca expansão geográfica, com fácil disseminação em regiões tropicais do mundo (Reis et al., 2017). O município de Campo Grande, Mato Grosso do Sul, está localizado em uma área de clima quente o que favorece a proliferação dos vetores de Leishmania spp. e, por consequência, transmissão do agente etiológico da leishmaniose. Segundo os dados da Gerência Estadual de Zoonoses/CECV/SGVS/SES de 2016, entre o ano de 2014 a 2016, 28.617 cães foram submetidos ao ensaio imunoenzimático indireto (ELISA) para o diagnóstico sorológico de leishmaniose, apresentando $28,3 \%$ de positividade.

Esta zoonose endêmica se apresenta com diversas manifestações clínicas no cão infectado, desde alterações cutâneas à alterações sistêmicas. O parasita é transmitido por meio da picada de fêmeas de flebetomíneos infectadas, sendo o cão reconhecido como o principal reservatório da LVC em ambiente urbano (Langoni et al., 2015). O sistema nervoso é composto pela barreira hematoencefálica que exibe uma estrutura que corresponde a separação do sistema nervo central SNC da circulação sistêmica, responsável por manter a função neuronal (Macau et al., 2017). Segundo Oliveira et al. (2017), a leishmania é capaz de atravessar a barreira hematoencefálica e disseminar-se pelo sistema nervoso através do líquido cefalorraquidiano (LCR) promovendo manifestações neurológicas e lesões no SNC.

Alterações neurológicas relacionadas à leishmaniose canina vêm sendo relatadas recentemente na medicina veterinária, no Brasil e em outros países (Macau et al., 2017; Oliveira et al., 2017; Zobba et al., 2017). Desta forma, este trabalho teve por objetivo relatar um caso de um cão positivo para Leishmania spp., com alterações neurológicas, diagnosticado na Clínica Veterinária da Universidade Anhanguera Uniderp em Campo Grande, Mato Grosso do Sul, área endêmica para LVC.

\section{Relato de caso}

Foi atendido na Clínica Veterinária da Universidade Anhanguera Uniderp um animal da espécie Canis lupus familiaris, fêmea, sem raça definida, com vacinações e vermifugações atualizados, com aproximadamente 1 ano e 6 meses, com histórico de quadro agudo de rigidez muscular, sialorreia e posição de opistótono, lesão em região de coxim plantar (Figura 1a).

A suspeita clínica inicial foi de tétano ou alterações na coluna vertebral, discopatia por compressão de região cervical e torácica. O exame clínico revelou que os parâmetros fisiológicos se encontravam dentro dos valores de normalidade. Associados à anamnese, exame físico e aos resultados negativos e 
não significativos de exame hematológicos, bioquímicos e de imagem de Raio-x foram descartadas as suspeitas clínicas de tétano e de alterações na coluna vertebral.

O exame físico específico de inspeção e palpação revelou lesões dermatológicas com áreas de alopecia localizada em ponta de orelha e aumento dos linfonodos poplíteos. Suspeitou-se de LVC e o exame parasitológico direto foi realizado por meio da técnica de punção aspirativa por agulha fina (PAAF) de linfonodo poplíteo. Foram visualizadas formas amastigotas de Leishmania spp., localizadas intracelularmente em macrófagos e posteriormente confirmada pela PCR dirigida ao gênero Leishmania spp. (Figura 1b).
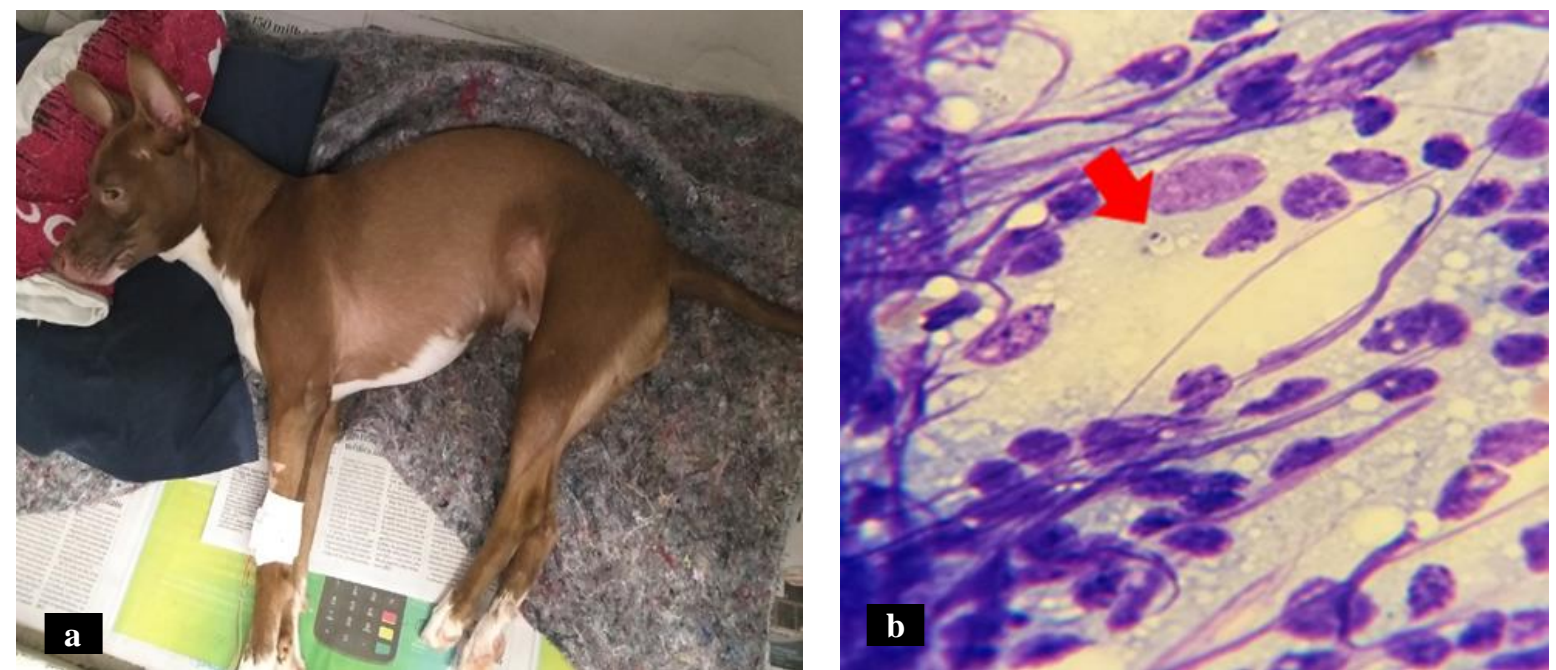

Figura 1. Quadro clínico do paciente. (a) Paciente manifestando tetania espástica e rigidez em membros torácicos e pélvicos. (b) Presença de forma amastigota de Leishmania spp., em macrófago.

\section{Resultados}

As manifestações clínicas mais comuns à doença são as descritas no relato de Montanha et al. (2013), e Abbiati et al. (2019), como lesões de pele, úlceras ao redor dos olhos e focinho, linfoadenomegalia, alterações hematológicas como trombocitopenia e alterações em leucograma. A caquexia também acompanha muitos acometidos pela infecção (Macau et al., 2017). O animal do presente relato apresentava lesões dermatológicas com áreas de alopecia localizada em ponta de orelha e aumento dos linfonodos poplíteos corroborando com estes autores.

Manifestações neurológicos na LVC vêm sendo relatadas recentemente, como no estudo de Giannuzzi et al. (2017), que descrevem os casos de dez cães naturalmente infectados por Leishmania spp., com acometimento do sistema nervoso central; semelhante ao relato de Macau et al. (2017), que em seu estudo revelou a habilidade do parasita de ultrapassar a barreira hematoencefálica e invadir o SNC, causando alterações neurológicas em diversas estruturas, como o telencéfalo, tálamo e hipocampo. Essas alterações são implicações decorrentes a uma inflamação causada pela infiltração de células mononucleares. O paciente, em estudo, apresentou sintomas de tetraplegia espástica e opistótono, sinais neurológicos de afecção do SNC com envolvimento de neurônios motores superiores.

O animal do estudo foi diagnosticado com LVC na forma neurológica, como provável agente causal Leishmania spp. O animal era vacinado contra cinomose, mas não foi realizada sorologia para toxoplasmose. Distúrbios neurológicos secundários à toxoplasmose não são comuns na espécie canina, o que reforça o diagnóstico presuntivo deste relato (Plugge et al., 2011). Zobba et al. (2017) relataram um paciente com LVC com manifestações neurológicas como ataxia, inclinação da cabeça e tremores, com presença de DNA Leishmania spp., em líquido cefalorraquidiano (LCR) detectado por meio da PCR. Cardinot (2013) pesquisou DNA de Leishmania spp., no SNC de cães positivos para Leishmaniose visceral e, após necropsia foi detectado DNA do parasita no sistema nervoso central de 23 animais com alterações neurológicas. Os resultados mostraram ainda a presença de DNA de Leishmania spp., no encéfalo de cães com leishmania visceral, sem sintomas neurológicos por meio da PCR. O LCR é coletado por meio da punção do espaço subaracnóideo após o paciente estar devidamente anestesiado. 
O tutor optou por tratar animal em uma clínica particular. Neste relato não foi utilizada amostra de LCR, que, por se tratar de um procedimento extremamente invasivo e de risco sua coleta não foi autorizada pelo tutor do animal.

Pode-se obter amostras para análises citológicas por diferentes técnicas e tecidos, raspado profundo de pele ou pela punção dos linfonodos, utilizando a técnica de punção aspirativa por agulha fina (PAAF), no diagnóstico da LVC. Também é possível coletar materiais de feridas ulceradas, sangue, conjuntiva, LCR, medula óssea e do SNC para pesquisa de Leishmania spp. (Abbiati et al., 2019; Chatzis et al., 2014; Monteiro et al., 2005; Schimming \& Silva, 2012; Zanette, 2006). Nesse estudo a LVC foi diagnosticada pelo exame parasitológico direto na análise citológica dos linfonodos poplíteos, pela PAAF e confirmado pela visualização das formas amastigotas de Leishmania spp., em macrófagos.

O diagnóstico definitivo do animal em estudo foi pela detecção de parasitas no interior dos macrófagos por meio de aspirados de linfonodos poplíteos. O PCR confirmou a presença do DNA de Leishmania spp., em amostra de linfonodo, sendo observada uma correlação positiva entre a carga parasitológica ao gene DNA, associado aos sinais clínicos (Galluzzi et al., 2018). O diagnóstico molecular correlacionado à Leishmania spp., é importante no diagnóstico definitivo e prognóstico do paciente. O diagnóstico molecular é eficiente mesmo em pacientes com carga parasitológica baixa, apresentando alta sensibilidade, técnica de eleição para o diagnóstico da LVC (Cabral, 2007; Oliveira et al., 2017). A PCR aumenta os níveis de positividade, considerada uma boa técnica na pesquisa e controle desta zoonose.

\section{Conclusão}

Leishmaniose visceral com sinais neurológicos é uma forma atípica de leishmaniose canina e deve ser considerada como diagnóstico diferencial, quando sintomas neurológicos estão presentes em caninos residentes nas áreas endêmicas à leishmaniose visceral.

\section{Agradecimentos}

Os autores agradecem o apoio da Fundação Oswaldo Cruz, Fiocruz MS, Uniderp e Funadesp.

\section{Referências bibliográficas}

Abbiati, T. C., Freitas, D. M., Alves, L. C., Freitas, B. G., Rezende, R. S., Barbosa, S. G., Jorge, A. L. T. A., Santos, S. M., \& Lopes, M. C. (2019). Leishmaniose visceral canina: Relato de caso. PUBVET, 13, 1-8. https://doi.org/10.31533/pubvet.v13n4a307.1-8

Cabral, A. W. D. (2007). Estudo comparativo entre o diagnóstico por técnicas sorológicas e da PCR para a detecção de Leishmania spp. Dissertação de Mestrado. Universidade Estadual de São Paulo. UNESP.

Cardinot, C. B. (2013). Identificação de DNA de Leishmania sp. no encéfalo de cães com Leishmaniose visceral. Universidade Estadual Paulista (UNESP).

Chatzis, M. K., Andreadou, M., Leontides, L., Kasabalis, D., Mylonakis, M., Koutinas, A. F., Rallis, T., Ikonomopoulos, J., \& Saridomichelakis, M. N. (2014). Cytological and molecular detection of Leishmania infantum in different tissues of clinically normal and sick cats. Veterinary Parasitology, 202(3-4), 217-225. https://doi.org/10.1016/j.vetpar.2014.02.044

Galluzzi, L., Ceccarelli, M., Diotallevi, A., Menotta, M., \& Magnani, M. (2018). Real-time PCR applications for diagnosis of leishmaniasis. Parasites \& Vectors, 11(1), 1-13. https://doi.org/10.1186/s13071-018-2859-8

Giannuzzi, A. P., Ricciardi, M., Simone, A., \& Gernone, F. (2017). Neurological manifestations in dogs naturally infected by Leishmania infantum: descriptions of 10 cases and a review of the literature. Journal of Small Animal Practice, 58(3), 125-138. https://doi.org/10.1111/jsap.12650

Langoni, H., Richini-Pereira, V. B., Scremin, C., Troncarelli, M. Z., Camargo, J. B., Machado, J. G., Ullmann, L. S., Guimarães, F. de F., Silva, D. B. da, \& Sánchez, G. P. (2015). Detección molecular de Leishmania spp. en material de hemocultivo, y diagnostico sorologico para leishmaniasis em perros del Barrio de la Conquista, São Manuel-SP, Brasil. Veterinária e Zootecnia, 22, 580-590. 
Macau, W. L., Sá, J. C., Silva, A. P. de C., Rocha, A. L., Mondêgo-Oliveira, R., de Andrade, F. H. E., Cunha, C. M., Calabrese, K. S., \& Abreu-Silva, A. L. (2017). Main lesions in the central nervous system of dogs due to Leishmania infantum infection. BMC Veterinary Research, 13(1), 1-4. https://doi.org/10.1186/s12917-017-1174-5

Montanha, F. P., Azevedo, M. G. P., Fernandes, T. S., Oshima, T. M., Remuszka, R. D. E., \& Santos, M. M. (2013). Leishmaniose canina-relato de caso. Revista Centífica Eletrônica de Medicina Veterinária, 20, 1-6.

Monteiro, E. M., Silva, J. C. F., Costa, R. T., Costa, D. C., Barata, R. A., Paula, E. V., Machado-Coelho, G. L. L., Rocha, M. F., Fortes-Dias, C. L., \& Dias, E. S. (2005). Leishmaniose visceral: estudo de flebotomíneos e infecção canina em Montes Claros, Minas Gerais. Revista Da Sociedade Brasileira de Medicina Tropical, 38(2), 147-152. https://doi.org/10.1590/s0037-86822005000200004

Oliveira, V. C., Boechat, V. C., Mendes Júnior, A. A. V., Madeira, M. de F., Ferreira, L. C., Figueiredo, F. B., Campos, M. P., de Carvalho Rodrigues, F. das C., Oliveira, R. asconcellos C., \& Amendoeira, M. R. R. (2017). Occurrence of Leishmania infantum in the central nervous system of naturally infected dogs: Parasite load, viability, co-infections and histological alterations. PloS One, 12(4), e0175588. https://doi.org/10.1371/journal.pone.0188150

Plugge, N. F., Ferreira, F. M., Richartz, R. R. T. de B., Siqueira, A., \& Dittrich, R. L. (2011). Occurrence of antibodies against Neospora caninum and/or Toxoplasma gondii in dogs with neurological signs. Revista Brasileira de Parasitologia Veterinária, 20(3), 202-206. https://doi.org/10.1590/s198429612011000300004

Reis, L. La, Balieiro, A. A. da S., Fonseca, F. R., \& Gonçalves, M. J. F. (2017). Changes in the epidemiology of visceral leishmaniasis in Brazil from 2001 to 2014. Revista Da Sociedade Brasileira de Medicina Tropical, 50(5), 638-645. https://doi.org/10.1590/0037-8682-0243-2017

Schimming, B. C., \& Silva, J. R. C. P. (2012). Leishmaniose visceral canina - Revisão de literatura. Revista Científica Eletrônica de Medicina Veterinária, 10(18), 1-5.

Zanette, M. F. (2006). Comparação entre os métodos de ELISA, imunofluorescência indireta e imunocromatografia para o diagnóstico da leishmaniose visceral canina. Universidade Estadual Paulista (UNESP).

Zobba, R., Evangelisti, M. A., Manunta, M. L., Alberti, A., Zucca, D., \& Parpaglia, M. L. P. (2017). A case of canine neurological leishmaniasis. Veterinaria Italiana, 53, 321-326. 10.12834/VetIt.307.1193.4

Recebido: 13 de abril, 2020

Aprovado: 20 de maio, 2020.

Disponível online: 7 outubro, 2020.
Licenciamento: Este artigo é publicado na modalidade Acesso Aberto sob a licença Creative Commons Atribuição 4.0 (CC-BY 4.0), a qual permite uso irrestrito, distribuição, reprodução em qualquer meio, desde que o autor e a fonte sejam devidamente creditados. 